\title{
Urgensi dan Peran Program Studi Komunikasi Penyiaran Islam
}

\section{Dalam Standarisasi Khatib}

\author{
A. Syarifudin \\ (Universitas Islam Negeri Raden Fatah Palembang. Email: \\ achmadsyarifudin73@radenfatah.ac.id)
}

\section{Siti Hajariyah}

(Kolej Universiti Islam Zainal Muhammad. Email: sitihajariyah@kuizm.edu.my)

\begin{abstract}
Abstrak: Standarisasi Khatib memiliki dua dimensi yang menyebabkan pro-kontra bagi para ulama, muballigh dan da'i. Sebagai upaya mewujudkan kompetensi dan kualifikasi yang baik bagi para khatib adalah hal yang sangat posisitf agar masyarakat pengguna (stake holder) menjadi tercerahkan. Jika ini yang diinginkan dari standarisasi, maka akan menjadi harapan dan keniscayaan bagi semua umat Islam. Melalui forum-forum silaturrahim kegiatan peningkatan kapasitas Khatib dapat dilakukan. Akan tetapi, jika standarisasi dijadikan sebagai upaya seleksi, penilaian kredibilitas terkait grade studi yang ditempuh, atau pembatasan materi khutbah, maka ini bertentangan dengan eksistensi dari para khatib dan eksistensi masjid yang ada di Indonesia. Sebab, masjid yang berdiri di negeri ini adalah swadaya masyarakat dan yang memilih orang-orang untuk menjadi khatib adalah seleksi berdasarkan ukuran moral dan kualifikasi religiusitas mereka. Maka dari itu, berdasarkan penelitian ini, standarisasi khatib belum diperlukan saat ini, dan Prodi Komunikasi Penyiaran Islam dipandang belum perlu melibatkan diri dalam persoalan standarisasi khatib.
\end{abstract}

Katakunci: Standarisasi, kompetensi khatib

\begin{abstract}
:
Standardization of the preacher has two dimensions that lead to the agree and contradiction of the ulama, the muballigh and da'i. As an effort to realize good competencies and qualifications for the preacher is a very positive thing so that the stake holders become enlightened. If this is desired from standardization, it will be a hope and necessity for all Muslims. Through gathering forums activities can be improved on preacher capacity. However, if standardization is used as an effort to select, assessing credibility regarding the grade of study taken, or limiting the material of the sermon, then this is contrary to the existence of the preacher and the existence of mosques in Indonesia. Because, mosques that stand in this country are self-help communities and those who choose people to become preacher are selection based on their moral size and religiosity qualifications. Therefore, based on this research, the standardization of preacher is not needed at this time, and Islamic Broadcasting Communication Study Program is deemed not necessary to involve itself in the issue of preacher standardization.
\end{abstract}

Keywords: Standardization, preacher competence

\section{Pendahuluan}


Fenomena mencuatnya beberapa da'i selebritis karena kemajuan teknologi terutaman media sosial seperti facebook, you tube, What's app, dsb, membuat dunia dakwah menjadi tersoroti. Ambil contoh "Mama Dedeh" yang ditayangkan Indosiar, ada lagi "Ustadz Maulana" dalam acara "Islam itu indah" yang juga populer dari aktifitas ceramahnya dishare melalui You tube. Masih banyak lagi yang mendulang sukses dalam berdakwah melalui media-media baru (new media). Di dalam kehidupan real masyarakat perkotaan, padatnya aktivitas seremonial yang ada menjadi faktor meningkatnya kebutuhan terhadap da'i yang bisa menyampaikan dakwah bi al-lisan khususnya.

Persoalannya, tidak sedikit di antara muballigh/da'i yang belum memiliki kapastitas ilmu dakwah yang baik, bahkan ilmu tentang ke-Islamannya juga masih sangat minim sehingga tidak jarang menimbulkan keresahan bagi sasaran dakwahnya. Misalnya, dulu pernah terjadi seorang narasumber sebuah acara keagamaan yang melakukan kesalahan dalam penulisan ayat al-Quran, maka sontak respon masyarakat meluas terlebih melalui viral saat ini. Acara yang ditayangkan oleh salah satu media cetak terkenal itu pun tak lepas dari hujatan dari kalangan umat Islam. Peristiwa itu pun berujung pada kredibilitas seorang Da'i. Pada saat lain, ketika seorang menyampaikan khutbah Jumat tanpa menggunakan buku khutbah dianggap kurang pas atau mendekati tidak sah.

Fenomena ini yang menjadi alasan bahwa Pemerintah perlu melakukan standarisasi bagi para Khatib itu terutama pada khutbah Jumat. Namun, sayangnya, wacana itu sontak menuai kritik dari berbagai kalangan; ulama, da'i, muballigh bahkan para anggota DPR merspon ini sebagai sesuatu yang perlu dicermati lebih serius. Selain itu, persoalan apa saja yang perlu distandarisasi, siapa yang berhak melakukan standarisasi, lalu bagaimana proses standarisasi itu bisa berlangsung adalah persoalan berikutnya.

Menurut Mastuki, Kementerian Agama tidak akan melakukan sertifikasi khatib. Kementerian Agama juga tidak akan mengintervensi materi khutbah. Merespon saran dan masukan dari masyarakat, Kementerian Agama sedang mempertimbangkan untuk melakukan standardisasi khatib Jumat. Maksud dari standardisasi, kata Mastuki, adalah memberikan kriteria kualifikasi atau kompetensi minimal yang harus dimiliki oleh seorang khatib Jumat agar khutbah disampaikan oleh ahlinya, serta sesuai syarat dan 
rukunnya. Dalam praktiknya, standardisasi juga tidak akan dirumuskan Kementerian Agama karena hal itu menjadi domain ulama."Hanya ulamalah yang memiliki otoritas, kewenangan, memberikan standar, batasan kompetensi seperti apa yang harus dipenuhi oleh seorang khatib dalam menyampaikan khutbah Jumat," ucapnya. ${ }^{1}$

Wacana tentang perlunya standarisasi Khatib paling tidak dilatarbelakangi oleh beberapa faktor antara lain: khotbah kerap menyalahkan agama lain. Ini sering terjadi di masjid perkampungan. Selain itu, saat pemilihan kepala daerah (pilkada) terkadang membuat khatib cenderung berpihak kepada salah satu calon dengan isi khotbah yang penuh kepentingan. Selain itu, khotbah yang sering mempersoalkan Pancasila sebagai thogut. "Kemenag sebagai representasi pemerintah tentunya ingin menempatkan agama pada posisi terhormat," katanya. Untuk menyikapi hal tersebut, Lukman mengaku sudah mengumpulkan perwakilan ormas Islam dan akademisi di bidang dakwah UIN. “Akhirnya muncul standardisasi dan sertifikasi.

Muncullah pro-kontra terhadap wacana standarisasi dan sertifikasi Khatib itu. Menurut Gus An'im, urusan Khatib atau penceramah dengan umat merupakan prerogatif lembaga keagamaan. Hal itu juga merupakan wilayah manusia dengan Tuhannya atau Ubudiyah, yang tak bisa diatur oleh siapa pun, termasuk negara. Jika kemudian standardisasi diberlakukan kepada para penceramah, hal tersebut akan berpotensi menyempitkan ruang dakwah dan syiar agama. ${ }^{2}$

Majelis Ulama Indonesia (MUI) menanggapi positif wacana sertifikasi khatib yang dikeluarkan Menteri Agama Lukman Hakim. Wakil Ketua Umum MUI Zainut Tauhid Sa'adi menjelaskan, MUI bisa memahami gagasan Menteri Agama bila maksud dari sertifikasi itu memenuhi tiga poin. Pertama, program sertifikasi khatib tersebut dimaksudkan untuk meningkatkan kapasitas, kapabilitas, dan kopetensi dai. "Baik dari aspek materi maupun metodologi," kata Zainut dalam keterangan tertulisnya, Senin, 6 Februari $2017 .^{3}$

Persoalan selanjutnya adalah mengenai siapa yang berhak melakukan standarisasi itu. Terlebih jika para Khatib adalah gelar/predikat yang diberikan oleh

\footnotetext{
${ }^{1}$ Jakarta (Pinmas), Kepala Pusat Informasi dan Humas (Pinmas) Kementerian Agama, Senin $(06 / 02)$.

${ }^{2}$ Dikutip dari https://nasional.tempo.co/read/844202/standardisasi-khatib-kiai-lirboyo-negarasudah-terlalu-jauh/full\&view= diakses pada September 2018.

${ }^{3}$ Dikutip dari https://m.tempo.co/read/843476/mui-tak-keberatan-pemerintah-sertifikasi-khatibsyaratnya/full\&view, pada Oktober 2018
} 
masyarakatnya langsung sebagai pengemban amanah memakmurkan masjid. Hal ini terkait dengan pernyataan Menteri Agama Lukman Hakim Saifuddin yang mengisyaratkan perlunya standardisasi khatib tersebut. Menurut Menag, wacana tentang ide atau gagasan tentang standardisasi khatib bukanlah baru; sebenarnya wacana itu adalah untuk merespons aspirasi yang berkembang di kalangan organisasi masyarakat (ormas) Islam dan tokoh-tokoh umat sendiri. "Mereka ingin pemerintah juga ikut hadir dalam menjamin kualitas mutu khutbah Jumat yang menjadi bagi tak terpisahkan dari shalat Jumat," kata Menag (Republika, 1/2/2017).

Untuk itu, wacana Standarisasi Khatib yang dahulu pernah trending perlu diteliti kembali dengan judul "standarisasi Khatib dan Peran Komunikasi Islam (Studi Pada Prodi KPI FDK UIN Raden Fatah Palembang).

\section{Metode}

Penelitian ini menggunakan metode deskriptif kualitatif dengan menggunakan wawancara kepada Pemerintah dalam hal ini Kementerian Agama Kantor wilayah Sumsel yakni bidang Penais. Sedangkan di Fakultas Dakwah wawancara dilakukan kepada Dekan, Kaprodi dan dosen KPI. Hasil wawancara itu dianalisis dan dideskripsikan sebagai hasil penelitian. Selain wawancara, dokumentasi beberapa hal terkait peran prodi KPI meliputi profil prodi dan Fakultas, serta analisis matakuliah yang relevan dengan Khatib.

\section{Diskusi Hasil}

\section{Dakwah dan Khutbah}

Secara bahasa dakwah adalah proses mengajak, menyeru, dari asal kata bahasa Arab دعا - يدعو - دعوة. Namun secara istilah dakwah mengandung beberapa arti yang beraneka ragam yang merupakan pendapat dari banyak ahli ilmu dakwah, mereka memberikan pengertian yang berbeda-beda sesuai dengan sudut pandang masingmasing dalam memberikan pengertian pada istilah tersebut, sehingga antara definisi yang satu dengan yang lainnya sering terdapat perbedaan dan persamaan, yaitu sebagai contoh :HSM. Nasarudin Latif, mendefinisikan dakwah "setiap usaha aktivitas dengan tulisan maupun lisan yang bersifat menyeru, mengajak, memanggil, manusia lainnya untuk beriman dan menaati Allah SWT. Sesuai dengan garis-garis akidah dan syariat 
serta akhlak Islamiyah". 4 Hamka mendefinisikan dakwah "seruan panggilan untuk menganut suatu pendirian yang ada dasarnya berkonotasi positif dengan substansi terletak pada aktivitas yang memerintahkan amar ma'ruf nahi mungkar. ${ }^{5}$ Ada unsurunsur penting yang terkandung di dalamnya antara lain: orang yang melakukan dakwah, sasaran dakwah, metode, media dan tujuan dakwah.

Abu Bakar Zakaria mengatakan dakwah "usaha para ulama dan orang-orang yang memiliki pengetahuan agama Islam untuk memberikan pengajaran kepada khalayak umum sesuai dengan kemampuan yang dimiliki tentang hal-hal yang mereka butuhkan dalam urusan dunia dan keagamaan. ${ }^{6}$

Pada dasarnya dakwah dimaksudkan untuk mewujudkan kesejahteraan dan kebahagiaan bagi umat manusia baik dalam kehidupan mereka didunia maupun diakhirat. RB, Khatib Pahlawan Kayo dalam bukunya Manajemen Dakwah, mengungkakan keberhasilan suatu kegiatan dakwah secara kuantitatif dapat diukur dengan standar dan kriteria sebagai berikut:

1. Kegiatan dakwah yang bertujuan untuk menegakkan amar ma'ruf nahi mungkar harus dilaksanakan bersama-sama (kelompok) secara terkoordinir dalam kesatuan organisasi yang kokoh, kuat dan rapi. Artinya kegiatan dakwah harus didukung oleh sejumlah organisasi dakwah yang kuat, karena dakwah akan gagal bila secara kuantitatif organisasi pendukungnya lemah.

2. Shalat sebagai pemegang fungsi terkuat yang membentengi diri agar terhindar dari tindakan-tindakan keji dan munkar, akan lebih afdhal bila dilaksanakan secara berjamaah. Falsafah shalat ini mengisyaratkan bahwa kekuatan jamaah untuk berdakwah harus diutamakan dari pada praktik dakwah sendiri-sendiri.

Jihad sebagai salah satu model kegiatan dakwah tidak hanya terfokus pada pertemuan saja, melainkan banyak sekali kegiatan lain yang digolongkan sama nilainya dengan jihad, seperti membela kebenaran dan keadilan dihadapan raja yang zalim, memelihara dan memuliakan kedua ibu bapak lebih-lebih dimasa tuanya, membela kepentingan fakir miskin dan anak-anak yatim, mempertahankan dan memelihara jiwa, akal, agama, harta, dan keturunan. Kenyataan ini memberikan pesan bahwa lapangan gerak dakwah itu tidak satu, tapi sangat banyak dan luas. Artinya secara kuantitatif

${ }^{4}$ Moh. Ali Aziz,Ilmu Dakwah, Jakarta: Kencana, h.5

${ }^{5}$ Wahidin Saputra, Pengantar Ilmu Dakwah, (Bandung: Rajawali Pers, 2008), h.2

${ }^{7}$ Ali Aziz, Ilmu Dakwah Edisi Revisi, Op.Cit, h. 11 
semakin luas jangkauan lapangan dakwah bermakna dakwah itu semakin baik. Begitu juga semakin banyak variasi kegiatan dakwah bermakna dakwah itu semakin sejuk dan merata. $^{7}$

Dalam melakukan aktivitas dakwah seorang da'i perlu mempunyai syarat-syarat dan kemampuan tertentu, agar bisa berdakwah dengan hasil yang baik dan sampai pada tujuannya. Persyaratan dan kemampuan yang perlu dimiliki oleh da'i secara umum bisa mencontoh kepada Rasulullah SAW, yang memang adalah Nabi terakhir yang di tunjuk oleh Allah untuk menjadi contoh bagi umat-Nya. Adapun syarat-syarat dan kemampuan secara teoritis yang harus dimiliki oleh seorang da'i adalah sebagai berikut:

a. Kemampuan berkomunikasi

b. Kemampuan menguasai diri

c. Kemampuan pengetahuan psikologi

d. Kemampuan pengetahuan pendidikan

e. Kemampuan pengetahuan bidang umum

f. Kemampuan dibidang Al-Qur'an

g. Kemampuan membaca Al-Qur'an dengan fasih

h. Kemampuan pengetahuan dibidang hadist

i. Kemampuan dibidang agama secara umum. ${ }^{8}$

Da'i disebut juga dengan juru dakwah atau lebih sering dikenal dengan komunikator dakwah, yaitu orang yang harus menyampaikan suatu pesan atau wasilah. Menurut Wahyu Ilaihi, M. A. Dalam “Komunikasi Dakwah”, untuk dikenal sebagai dai atau komunikator dakwah itu dapat dikelompokkan menjadi dua ${ }^{9}$, yaitu: a) Secara umum adalah setiap muslim atau muslimah yang mukallaf (dewasa) dimana kewajiban dakwah merupakan suatu yang melekat tidak terpisahkan dari misinya sebagai penganut Islam, sesuai dengan perintah "Sampaikan walau satu ayat". Secara Khusus adalah mereka yang mengambil keahlian khusus (mutakhasis) dalam bidang agama Islam, yang dikenal dengan panggilan ulama

\section{Khutbah Sebagai Media Dakwah}

${ }^{7}$ RB. Khatib Pahlawan Kayo, Manajemen Dakwah, (Jakarta: Amzah, 2007), h.87-88

${ }^{8}$ Slamet Muhaemin Abda, Prinsip-Prinsip Metodelogi Dakwah, (Surabaya: Usaha Nasional, 1994), Cet.ke-1, h.69

${ }^{9}$ Wahyu Ilaihi, Komunikasi Dakwah, (Bandung: PT Remaja Rosdakarya, 2010), h. 77 
Khutbah merupakan bentuk public speaking yang dilakukan oleh khatib guna menyampaikan tausiyah keagamaan, berisi informasi tentang keimanan, syari'ah dan akhlak agar pendengar (audiens) memperoleh ilmu baru atau upgrading informasi agar meningkat pengetahuan, motivasi keagamaan. Berbeda dengan ceramah atau tabligh pada umumnya, Khutbah yang disampaikan melalui mimbar pada jumat atau hari Raya terikat dengan ketentuan-ketentuan khusus baik menyangkut materi khutbah, kaifiyat dan yang menyampaikannya (Khatib).

Salah satu media dakwah dalam agama Islam adalah melalui khutbah Jumat merupakan ritual ke agamaan yang memiliki jangka waktu yang relatif sering dilakukan yakni seminggu sekali. Khutbah Jumat dijadikan sebagai sarana untuk membangkitkan iman dan taqwa umat Islam khususnya kaum laki-laki wajib baginya menjalankan shalat Jumat.

Pelaksanaan sholat Jum'at merupakan karakteristik miniatur masyarakat yang islami. sekaligus sebagai ciri khas dan karakter umat muslim sebenarnya. dalam sholat Jum'at diliputi dengan penuh pensucian, pengagungan dan ganjaran pahala yang tinggi.Maka, ketika adzan dikumandangkan maka setiap manusia segera bergegas menuju mMsjid dan sejenak meninggalkan segala bentuk aktifitas untuk melaksanakan sholat Jum'at. Ada kandungan ayat Al - Qur'an menerangkan tentang kewajiban melaksanakan perintah sholat Jum'at dalam Q.S al-Jumu'ahayat 9:

Hai orang - orang yang beriman, apabila diseru untuk menunaikan shalat pada hari Jum'at, maka besegeralah kalian untuk mengingat Allah dan tinggalkan jual beli.Yang demikian itu lebih baik bagi kalian jika kalian mengetahui.(QS.Al Jumu'ah: 9)

Kewajiban ibadah jum'at mulai disyariatkan pertama kali semenjak turunya surat Al-Jumu'ah ayat 9, yaitu di Madinah. Perihal tempat diturunkanya ayat tersebut tidak dipersilihkan. Dengan demikian, mulai ditetapkanya sholat jum'at itu di Madinah bukan di Mekkah.

Komunikasi yang cakap atau cerdas dalam al-qur'an diistilahkan dengan qaulan karima, qaulan baligha, qaulan layyina, qaulan ma'rufa, qaulan sadida dan qaulan maysura. Untuk mencapai itu, prinsip-prinsip yang perlu disikapi baik oleh komunikator maupun komunikan harus simultan, karena masing-masing memiliki peran yang saling mengisi dan saling melengkapi. Menurut Abu darda, misalnya, prinsip pertama adalah manis tutur kata dan inklusif. Tutur kata yang manis merupakan daya tarik tersendiri 
dalam berkomunikasi, karena dalam pepatah dikatakan barang siapa yang manis tutur katanya maka banyak temannya. Bahkan penggunaan kata "kita" akan lebih menciptakan suasana akrab dari pada kata "mereka", atau "kamu", termasuk di dalamnya adalah menghindari kata-kata atau istilah yang dapat menyinggung perasaan komunikan, seperti pantangan suatu adat atau daerah tertentu, kata-kata jorok, porno, seronok, dan sejenisnya. Selain itu, prinsip yang perlu diperhatikan adalah kontroling terhadap ucapan dan perilaku. Control ucapan maksudnya adalah, mengontrol ucapan sebelum berbicara, apakah dapat menimbulkan ketersinggungan orang lain atau tidak. Dalam pepatah disebutkan, al-kalamu yanfuzu ma la tanfuzu alibaru : perkataan itu dapat menembus apa yang tidak tertembus oleh jarum. ${ }^{10}$

Tujuan ini didasarkan pada firman Allah dalam Q.S. al-Baqarah/2: 257, “Allah Pelindung orang-orang yang beriman, Dia mengeluarkan mereka dari kegelapan (kekafiran) kepada cahaya (iman). Dan orang-orang kafir, pelindung-pelindungnya adalah setan, yang mengeluarkan mereka dari cahaya kepada kegelapan (kekafiran). Mereka itu adalah penghuni neraka, mereka kekal di dalamnya." Pada ayat sebelumnya disebutkan bahwa seseorang yang ingkar pada Thagut dan beriman kepada Allah, maka ia berpegang pada tali yang amat kuat dan tidak akan putus, tujuan dakwah tersebut sangat sejalan dengan pengertian dakwah yang dikemukakan oleh Bakhyul Khûlî dalam karyanya Tadzkirat al-Du'ât, yaitu dakwah adalah memindahkan manusia dari suatu situasi ke situasi yang lain. Tentunya dari situasi negatif ke situasi positif atau dari yang positif kepada yang lebih positif lagi. Menurut al-Raghib al-Ishfahânî, istilahzhulumât dalam ayat ini mengandung dua makna, yaitupertama kegelapan, dankedua kebodohan, kemusyrikan dan kefasikan. Makna kedua menurutnya dapat dilihat dalam Q.S. Ibrâhîm/14:5. Muhammad 'Alî al-Shabunî melihat bahwa lafazhzhulumâtyang terdapat pada ayat 1 dan 5 surah Ibrâhîm bermakna kebodohan, kesesatan dan kekafiran.

\section{Pro dan Kontra Seputar Standarisasi dan Sertifikasi Khatib}

Di Mataram, sebuah penelitian menegaskan bahwa saat ini sertifikasi khatib belum perlu diterapkan. Pasalnya, tidak ada bukti kuat yang menunjukkan adanya radikalisasi di tengah masyarakat Mataram akibat dari khotbah Jumat. Namun demikian,

\footnotetext{
${ }^{10}$ Syarifuddin, A. "DAKWAH KOMUNIKATIF, KENAPA TIDAK?." Wardah: Jurnal Dakwah dan Kemasyarakatan 16.1 (2015): 53-62.
} 
para responden menekankan pentingnya upaya standarisasi dalam segala aspek keagamaan, terutama pada aspek manajemen masjid dan managemen kelembagaan keagamaan di bawah pembinaan Kementerian Agama RI dan organisasi kemasyarakatan Islam. ${ }^{11}$ Penelitian ini memperoleh hasil bahwa: Pertama, Sertifikasi tidak menjadi sesuatu yang urgen untuk konteks saat ini, dimana masyarakat memberikan keleluasan kepada para khatib untuk menyampaikan materi khutbahnya yang sesuai dengan tuntunan syariat agama Islam. Khatib itu gelar keagamaan yang orientasi utamanya adalah ibadah sehingga klaim adanya muatan radikasilme atau penyebab munculnya radikalisme atas nama agama tidak dipengaruhi oleh materi khutbah khatib di atas mimbar. Kedua, Respon mayoritas khatib di Kota Mataram tentang sertifikasi khatib adalah kurang bijak dan kurang tepat pemerintah mensertifikasi khatib karena khatib itu merupakan tugas informal masyarakat dalam menyampaikan pesan ibadah keagamaan, dan khatib menjadi prasyarat sahnya ibadah Jumat.

Dengan demikian sertifikasi akan berdampak terhadap keberlangsungan ibadah Jumat jika sewaktu-waktu khatib yang disertifikasi tidak hadir. Sertifikasi akan bermasalah pada aspek siapa dan bagaimana mekanisme sertifikasi khatib, dengan jumlah khatib yang begitu banyak menyebar di Indonesia. Ini menambah beban pemerintah jika semua itu diberikan anggaran. Usulan para khatib kepada pemerintah agar khatib lebih diberdayakan dengan mengadakan kursus-kursus metode dakwah, pelatihan-pelatihan skill secara berkala dan berkesinambungan. Dengan cara seperti ini pemerintah bisa membuat mekanisme standarisasi khatib dan khutbah yang layak untuk diorbitkan dan dipublikasikan di tengah-tengah masyarakat. ${ }^{12}$

Penelitian yang dilakukan Arsam tentang Persepsi Para Mubaligh Persepsi Para Mubaligh Persepsi Para Mubaligh Terhadap erhadap Wacana Kontroversi Standardisasi acana Kontroversi Standardisasi acana Kontroversi Standardisasi Khatib dan Sertifikasi Mubaligh Khatib dan Sertifikasi Mubaligh (Studi Terhadap Para Mubaligh terhadap Para Mubaligh di Banyumas) menyimpulkan bahwa: a) mendukung adanya standardisasi khatib dan sertifikasi mubaligh dengan catatan dimulai dengan adanya

\footnotetext{
${ }^{11}$ Fahrurrozi, Sertifikasi atau Standarisasi Khatib? Respons Para Da'i di Kota Mataram, Jurnal Komunikasi Islam | ISBN 2088-6314 | Terakreditasi Menristekdikti SK. NO. 2/E/KPT/2015 | Volume 08, Nomor 01, Juni 2018 Diakses pada Oktober 2018.

${ }^{12}$ Ibid., h. 175-176
} 
pelatihan dan mendapatkan gaji dari pemerintah. b). Pandangan yang menolak adanya standardisasi khatib dan sertifikasi mubaligh. Kedua istilah tersebut dipandang tidak tepat dan yang lebih tepat adalah dibentuknya forum silaturrahim antar mubaligh dan khatib yang di dalamnya diisi dengan sharing sharing seputar problematika mubaligh dan keumatan. c). Pandangan alternatif yaitu memberikan alternatif baru dengan memberdayakan penyuluh agama yang ada di lingkungan Kementerian Agama untuk mendampingi para mubaligh atau membentuk forum silaturrahim antar mubaligh dan khatib. ${ }^{13}$

Sebagaimana namanya Komunikasi Islam, maka kegiatan komunikasi harus dilakukan berdasarkan nilai-nilai etika yang dianut dalam sebuah masyarakat, hal ini dimaksudkan agar komunikasi yang dilakukan menyenangkan, memberi kebaikan dan memberi manfaat bagi pelaku komunikasi. Islam sebagai agama rahmat, ajarannya diyakini memberi kebaikan dalam kehidupan umat manusia. Islam juga menempatkan komunikasi sebagai sesuatu yang penting dan bernilai ibadah apabila komunikasi itu dilakukan berdasarkan nilai-nilai yang terdapat dalam alquran dan sunnah Nabi SAW, keduanya merupakan pedoman yang berisi tuntunan hidup bagi setiap muslim yang harus dijunjung tinggi dan menjadi ukuran-ukuran dalam berkomunikasi. Etika komunikasi islami dimaksudkan sebagai sebuah nilai-nilai yang baik yang pantas dan memiliki manfaat ketika melakukan proses komunikasi, apakah komunikasi itu berupa komunikasi interpersonal, komunikasi kelompok, komunikasi organisasi atau komunikasi massa kesemua bentuk komunikasi yang akan dilakukan tersebut harus didasarkan pada nilainilai alquran dan sunnah Nabi SAW. Nilai-nilai etika komunikasi islami yang tertuang dalam alquran dan sunnah Nabi SAW meliputi nilai-nilai kejujuran (kebenaran). Nilai kejujuran ini meliputi nilai-nilai keadilan, kewajaran dan kepatutan. Etika komunikasi yang lain adalah nilai Falyakul Khairan au liyasmut (Katakan yang baik atau diam), selanjutnya yang terakhir adalah nilai tabayyun. Ketiga nilai etika

13 Arsam, Persepsi Para Mubaligh Persepsi Para Mubaligh Persepsi Para Mubaligh Terhadap erhadap Wacana Kontroversi Standardisasi acana Kontroversi Standardisasi acana Kontroversi Standardisasi Khatib dan Sertifikasi Mubaligh Khatib dan Sertifikasi Mubaligh (Studi Terhadap Para Mubaligh terhadap Para Mubaligh di Banyumas), KOMUNIKA, Vol. 11, No. 2, Juli - Desember 2017 diakses pada September 2018. 
komunikasi islami ini merupakan pendidikan berkomunikasi bagi setiap muslim dalam menciptakan komunikasi yang baik menurut ajaran Islam. ${ }^{14}$

Komunikasi Islami mengajarkan manusia menegakkan nilai-nilai kejujuran (kebenaran) dalam berkomunikasi, kemudian dalam berkomunikasi didasarkan pada perkataan yang baik (Falyakul Khairan au liyasmut), selain itu komunikasi islami juga menuntut seorang komunikator untuk teliti dan cermat dalam memahami sebuah informasi atau pesan yang diterimanya sebelum melanjutkannya kepada orang lain (nilai tabayyun). Ketiga nilai-nilai tersebut merupakan modal utama dan sebagai ukuran bagi setiap muslim dalam melakukan komunikasi, hal itu dimaksudkan agar proses komunikasi yang berlangsung mendatangkan suatu baikan dan keselamatan serta kebahagian bagi kehidupan umat manusia. ${ }^{15}$

Secara faktual, saat ini di Indonesia, para Khatib tidak memperoleh SK atau tugas khusus dan memperoleh gaji dari Pemerintah sehingga untuk memberlakukan strandarisasi, masih belum perlu dilakukan. Di samping itu, kebutuhan akan para Khatib mengingat rasio banyaknya Masjid di Indonesia menjadi faktor belum perlu nya dilakukan standarisasi apalagi sertifikasi. Akan tetapi, pembekalan untuk para Khatib terkait dengan rukun dan syarat-syarat nya mereka perlu melakukan improvisasi melalui workshop-workshop/pelatihan dan meningkatkan pengetahuan tentang khutbah dan peningkatan skill tentang khatib.

Dalam penyampaian pesan tabligh juga diperlukan adanya metode dan strategi, salah satu metode pengembangan dakwah melalui media, dengan cara memilih media yang relevan dan menunjang proses dakwah, salah satunya internet. Selain itu ada beberapa cara yang mesti dilakukan oleh seorang muballigh dalam menyampaikan dakwah, antara lain:Khutbah merupakan salah satu bentuk dakwah bil lisan, dakwah ini dilakukan dengan menggunakan lisan antara lain: - Qoulan ma"rufun, yaitu dengan berbicara dalam pergaulan sehari-hari yang disertai misi agama yaitu agama Allah. Mudzakarah, yaitu mengingatkan orang lain jika berbuat salah, baik dalam ibadah maupun perbuatan. - Nasihatudin, yaitu memberikan nasihat kepada orang yang tengah dilanda problema kehidupan. - Majlis ta"lim, yaitu seperti pembahasan tentang kitab dan berakhir dengan dialog. - Pengajian umum, yaitu berdebat dengan menggunakan

\footnotetext{
${ }^{14}$ Susanto, Joko. "ETIKA KOMUNIKASI ISLAMI." Jurnal WARAQAT • Volume I, No. 1, Januari-Juni 2016, E-Journal STAI As-Sunnah Deli Serdang 1.1 (2016): 1-24.

${ }^{15}$ Ibid., h. 23
} 
argumentasi serta dengan di akhir kesempatan bersama dengan menarik satu kesimpulan.

Sementara itu, di Palembang standarisasi Khatib belum perlu dan belum mendesak untuk dilaksanakan. ${ }^{16}$ Namun jika pemerintah mengeluarkan surat edaran dan perintah maka pihak Kemenag Provinsi pun harus siap untuk melakukan itu. Tanggapan Dekan Fakultas Dakwah dan Komunikasi UIN pun senada dengan mengatakan bahwa standarisasi Khatib jika akan dilaksanakan harus mempertimbangkan dampak bagi yang tidak lolos standarisasi dan sertifikasi. ${ }^{17}$ Bahkan kesempatan untuk menjadi Khatib tidak mesti alumnus dari prodi KPI, bisa saja dari fakultas Tarbiyah, Syariah, Ushpi, dsb. Silahkan berkompetisi untuk menjadi Khatib yang kualified. Namun, menurut salah seorang Dosen KPI menyatakan bahwa sesungguhnya standarisasi Khatib itu bisa secara implisit diterapkan dalam matakuliah Ilmu Dakwah, Retorika, Komunikasi Dakwah dan teknik Pidato. ${ }^{18}$ Prodi KPI saat ini ingin mencetak alumni nya menjadi sarjana yang kompetitif dalam bidang humas, broadcasting dan advertising.

\section{KPI Sebagai Agen Transformasi Khatib Berkualitas}

Salah satu implikasi yang dapat diperoleh dari sistem komunikasi yang Islami secara epistimologis berkaitan dengan kemapanan keilmuan menyangkut bagaimana batasan dan cara mengetahui sistem komunikasi Islam, dengan kata lain mempersoalkan objek materia dan forma sistem komunikasi Islam dalam dakwah. Yang kedua dalam ontologis keilmuan sistem komunikasi Islam, hal ini berarti mendasarkan pada apaapa saja yang harus diketahui dan dipelajari, dengan kata lain mempersoalkan pembidangan, rincian disiplin sistem komunikai Islam serta metodologi yang digunakan untuk pengembangan dakwah melalui sistem komunikasi Islam. Ketiga berkaitan dengan axiologis yaitu kemanfaatan sistem komunikasi Islam dalam Kegiatan Dakwah Islamiyah. Dengan mendasarkan pada implikasi keilmuan tersebut, maka kegiatan dakwah tidak hanya berorientasi pada kegiatan praktis melainkan sebagai suatu sebagai sistem yang menjelaskan interaksi antar unsur komunikasi dakwah serta problem interaksi tersebut. Selanjutnya implikasi yang terbentuk dalam kemanfaatan sistem

\footnotetext{
${ }^{16}$ Hasil Wawancara dengan Penais Kemenag Kanwil Provinsi Sumsel di Palembang, pada September 2018.

${ }^{17}$ Hasil Wawancara dengan Dekan FDK UIN Raden Fatah Palembang, September 2018.

${ }^{18}$ Hasil wawancara dengan Anang Walian, dosen pengampuh matakuliah retorika Dakwah, September 2018.
} 
komunikasi islam atau dakwah melahirkan alternatif problem solving dalam menyelesaikan problem kemasyarakatan melalui sistem komunikasi Islam baik dengan memanfaatkan sistem pers dakwah maupun sistem teknologi dakwah secara integral dan komprehensif. ${ }^{19}$

Mengacu pada PPno19tahun2005inimaka dapat disimpulkan bahwa: - Standar Kompetensi Lulusan bukan saja merupakan kompetensi mata pelajaran yang telah dirancang oleh program studi belaka tetapi juga mencakup sikap, pengetahuan dan keterampilan. - Standar Kompetensi Lulusan bertujuan mempersiapkan lulusan selain dapat menemukan,mengembangkan,menerapkanilmu,teknologi,danseniyangbermanfaat juga lulusan diharapkan berakhlak mulia dan mandiri, - Standar Kompetensi Lulusan perguruan tinggi ditentukan oleh masing-masing perguruan tinggi. - Standar kompetensi lulusan (SKL) dirancang berdasarkan masukan dari stakeholder internalmaupuneksternalsertaSWOTanalysis,kemudiandisusunKurikulum,method ofdeliverydanassessmentnyasehinggaprosespembelajaransecarakeseluruhandapat memberikan kompetensi yang diinginkan pada lulusan.

Dengan ini maka program studi KPI dapat menempatkan dirinya dalam seluruh lini kehidupan. Namun seiring berkembangnya prodi-prodi lain misalnya Manajemen Dakwah dan Pengembangan masyarakat Islam. Dapat dimungkinkan peran dakwah dan secara spesifik bagi pengembangan dakwah prodi-prodi yang baru tersebut diharapkan lebih banyak mengambil peran. Sedangkan KPI sendiri lebih memfokuskan dirinya pada pengembangan broadcasting, kehumasan, dan keahlian sejenis.

\section{Penutup}

Standarisasi Khatib belum perlu dilakukan karena beberapa faktor antara lain Pemerintah belum mampu menkaver seluruh kebutuhan hidup mereka jika para Khatib menjadi tanggungan Pemerintah. Selain itu banyaknya masjid/mushalla menjadi penyebab banyaknya kebutuhan akan eksistensi Khatib sehingga keberadaannya sangat urgen bagi umat Islam di Indonesia. Selain itu, Prodi Komunikasi Penyiaran Islam belum perlu untuk standarisasi Khatib karena orientasi lulusan Prodi KPI UIN Raden Fatah bukanlah untuk menghasilkan sarjana bidang da'i atau Khatib secara spesifik.

19 Hasyim Hasanah, ARAH PENGEMBANGAN DAKWAH MELALUI SISTEM KOMUNIKASI ISLAM, AT-TABSYIR: Jurnal Komunikasi Penyiaran Islam, Vol. 4, No. 1 Juni 2016, h. 153 
Namun seandainya mereka para lulusan KPI yang ingin menekuni bidang tabligh, teoriteori yang disajikan dalam matakuliah terkait keterampilan public speaking cukup menjadi bekal dalam masyarakat. Pihak Fakultas Dakwah dan Komunikasi agar menyambut sinyal dan peluang pengembangan Prodi terutama terkait dengan peningkatan skill public speaking. Fakultas dapat mengembangkan skill kedakwahan, kompetensi SDM dalam bidang penyiaran Islam, melalui kegiatan-kegiatan pelatihan dan profesionalisme.

Rekomendasi kepada pihak Pemerintah dalam hal ini Kemenag RI agar mengimbangi setiap kebijakan yang akan diterapkan, meskipun terkadang berbasis wacana namun sangat berdampak kepada masyarakat luas karena sebagai pemegang otoritas dalam urusan keagamaan dan bersentuhan langsung dengan khalayak ramai.

\section{Daftar Pustaka}

Abda, Slamet Muhaemin, (1994) Prinsip-Prinsip Metodelogi Dakwah, Surabaya: Usaha Nasional), Cet.ke.1.

Aziz, Moh. Ali, (2004) Ilmu Dakwah, Jakarta: Kencana,.

Arsam, Persepsi Para Mubaligh Persepsi Para Mubaligh Persepsi Para Mubaligh Terhadap erhadap Wacana Kontroversi Standardisasi acana Kontroversi Standardisasi acana Kontroversi Standardisasi Khatib dan Sertifikasi Mubaligh Khatib dan Sertifikasi Mubaligh (Studi Terhadap Para Mubaligh terhadap Para Mubaligh di Banyumas), KOMUNIKA, Vol. 11, No. 2, Juli - Desember 2017.

Baiti, R., \& Razzaq, A. (2014). Teori dan Proses Islamisasi di Indonesia. Wardah, 15(2), 133-145. Retrieved from http://jurnal.radenfatah.ac.id/index.php/warda/article/view/193.

Fahrurrozi, Sertifikasi atau Standarisasi Khatib? Respons Para Da'i di Kota Mataram, Jurnal Komunikasi Islam | ISBN 2088-6314 | Terakreditasi Menristekdikti SK. NO. 2/E/KPT/2015 | Volume 08, Nomor 01, Juni 2018 Diakses pada Oktober 2018.

Hasyim Hasanah, ARAH PENGEMBANGAN DAKWAH MELALUI SISTEM KOMUNIKASI ISLAM, AT-TABSYIR: Jurnal Komunikasi Penyiaran Islam, Vol. 4, No. 1 Juni 2016.

Ilaihi, Wahyu,(2010) Komunikasi Dakwah, (Bandung: PT Remaja Rosdakarya,.

Kayo, RB. Khatib Pahlawan, (2007Manajemen Dakwah, Jakarta: Amzah,. 
Mastuki, Kepala Pusat Informasi dan Humas (Pinmas) Kementerian Agama, Wacana sertifikasi Khatib, Jakarta, Senin (06/02).

Razzaq, A. (2015). DINAMIKA DAKWAH DAN POLITIK DALAM PEMIKIRAN ISLAM MODERNIS DI INDONESIA. Wardah, 15(1), 7-15. Retrieved from http://jurnal.radenfatah.ac.id/index.php/warda/article/view/202

Razzaq, A., \& Saputra, D. (2016). Studi Analisis Komparatif Antara Ta'wil dan Hermeneutika dalam Penafsiran al-Qur'an. Wardah, 17(2), 89-114. Retrieved from http://jurnal.radenfatah.ac.id/index.php/warda/article/view/961

Saputra, Wahidin, (2008) Pengantar Ilmu Dakwah,Bandung: Rajawali Pers.

Syarifuddin, A. "DAKWAH KOMUNIKATIF, KENAPA TIDAK?." Wardah: Jurnal Dakwah dan Kemasyarakatan,2015, Vol.16. No.1

Susanto, Joko. (2016). "ETIKA KOMUNIKASI ISLAMI." Jurnal WARAQAT • Volume I, No. 1, Januari-Juni 2016, E-Journal STAI As-Sunnah Deli Serdang 1.1

https://nasional.tempo.co/read/844202/standardisasi-khatib-kiai-lirboyo-negara-sudahterlalu-jauh/full\&view.

https://m.tempo.co/read/843476/mui-tak-keberatan-pemerintah-sertifikasi-khatibsyaratnya/full\&view. 